\title{
The uses and applications of hydrogen processing for titanium additive manufacturing
}

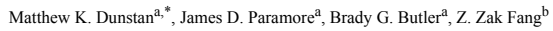 \\ ${ }^{a}$ United States Army Research Laboratory, 4600 Rodman Rd., FCDD-RLW-MF Aberdeen Proving Ground, Maryland 21005, USA \\ ${ }^{\mathrm{b}}$ Department of Metallurgical Engineering, the University of Utah, 135 South 1460 East Room 412, Salt Lake City, Utah 84112, USA \\ *Cooresponding Author: matthew.k.dunstan.ctr@mail.mil; mkdunstan10@gmail.com
}

$\underline{\text { Abstract }}$

Additive manufacturing has shown to be a promising method for reducing the cost and increasing the complexity of titanium components, with the majority of research focusing on beam-based methods (i.e. powder bed fusion and directed energy deposition). However, these processes produce highly complex thermal histories, which can result in highly anisotropic and otherwise undesirable microstructures and mechanical properties. In an effort to mitigate these challenges, the use of hydrogen as a temporary alloying element has been identified as a promising method to prevent unfavorable microstructures and isotropy in AM Ti-6Al-4V. Herein, the powder metallurgy process known as Hydrogen Sintering Phase Transformation (HSPT) used in conjunction with a solid state AM method known as fused filament fabrication (FFF) is discussed.

\section{Introduction}

In typical titanium processing, hydrogen is viewed as a contaminant to avoid, as it acts to embrittle titanium and, in high enough concentrations, forms the very brittle titanium hydride ( $\mathrm{TiH}_{2}$ ) $\delta$ phase [1]. However, in recent years hydrogen has shown to be a useful temporary alloying element for titanium alloys $[2,3,4]$. Specifically, the powder metallurgy process known as hydrogen sintering phase transformation (HSPT) has shown to produce Ti-6Al-4V components with an ultra-fine grained microstructure, relative density $>98 \%$, and low levels of hydrogen ( $<10 \mathrm{ppm})$ in the as-sintered state $[5,6,7]$.

During HSPT processing, $\mathrm{TiH}_{2}$ powders are mixed with an Al-V master alloy, compacted, and sintered in a dynamically controlled hydrogen atmosphere. By utilizing titanium hydride powders, interstitial contamination is reduced and densification kinetics are improved $[2,3,4]$. By utilizing a hydrogen sintering atmosphere, the material is forced through phase transformations that produce an ultrafine grained microstructure, which would not be possible in traditional vacuum/inert sintering [8]. Furthermore, the unique morphology of the microstructure allows for wrought-like globular or bimodal microstructures to be formed through simple vacuum/inert annealing steps that require no additional hydrogen or thermomechanical processing. This wide range of microstructures has given way to tensile and fatigue properties that compete with traditional wrought processed Ti-6Al-4V $[9,10]$.

With the rise in popularity of additive manufacturing (AM), the question has been raised whether or not the HSPT process can be used in conjunction with AM. The most common AM methods used with titanium include selective laser melting (SLM), electron beam melting (EBM), and direct energy deposition (DED). In all of these methods a beam of energy (in the form of a laser or electron beam) is used to selectively melt the titanium in discrete layers. This repeated melting and solidification often leads to undesirable microstructures, high levels of anisotropy, and poor mechanical properties [11]. To combat these issues, the HSPT process has been identified as a way to combat these issues through the fused filament fabrication (FFF) AM method.

FFF or fused deposition modeling (FDM), is the most commonly known AM method to the general population and is frequently referred to as 3D printing. FFF typically consists of a thermoplastic polymer filament that is extruded through a heated print head and deposited onto a print bed in a layer wise manner. In recent years, plastic FFF has seen a dramatic increase in popularity for home hobbyists, as machine costs have significantly reduced due to the original patents expiring. Typically, FFF is used solely for thermoplastics such as polylactic acid (PLA) and acrylonitrile butadiene styrene (ABS). However, the FFF method has been used for metals and ceramics since the 1990's and was first known as the Fused Deposition of Metals (FDMet) or Fused Deposition of Ceramics (FDC) [12, 13, 14, 15]. In these processes, a metal and/or ceramic powder is mixed with a polymeric binder, extruded into a filament, and printed using standard FFF methods. The binder in the printed component is them removed through chemical and/or thermal debinding steps and the part is subsequently sintered to produce a densified metal and/or ceramic part. In essence, this process can be described as free-form metal/ceramic injection molding.

With increased popularity of plastic-based FFF, there has also been an increase in research of FFF to produce metals and ceramics [16, 17, 18, 19, 20]. However, a major problem that plagues FFF for metals and ceramics is that of filament flexibility. The presence of the metal and/or ceramic powders causes the filament to become stiff and often brittle, which prevents it from being spooled and causes the filament to break during printing. To mitigate these issues, a complex binder system is typically required.

In this work, a simple two-component binder is used to produce filament with (Ti-6Al-4V)-H powder that is used in conjunction with the HSPT process to produce ultra-fine grained Ti-6Al-4V. The debinding characteristics, microstructure, interstitial contamination, and printability are examined.

(C) The Authors, published by EDP Sciences. This is an open access article distributed under the terms of the Creative Commons Attribution License 4.0 (http://creativecommons.org/licenses/by/4.0/). 


\section{Materials \& Methods}

The binder in this work consisted of a thermoplastic elastomer (TPE) and mineral oil (MO). Filament was produced by hand mixing hydrogenated pre-alloyed Ti-6Al-4V powders, (Ti-6Al-4V)-H, supplied by AMETEK Specialty Metal Products (-200/+500 mesh), with the TPE/MO. The mixture was then compounded and extruded using a Thermo Fischer Process 11 at various temperatures and speeds. The screw design of the compound extruder consisted of a conveying zone, a mixing zone with elements at $90^{\circ}$, and a final conveying zone leading to the extrusion die, which had a diameter of 3 mm. The total screw design had a length to diameter ratio of $6.25: 1$

The prepared filaments were printed using a Lulzbot Taz 5 with a custom-built pinch roller print head. A print nozzle diameter of $1.2 \mathrm{~mm}$ was used. Extruded filament and printed parts were debound and sintered in a custom built tube furnace using a modified HSPT process, as shown in Figure 1. Debinding consisted of slowly heating the furnace at a rate of $1{ }^{\circ} \mathrm{C} / \mathrm{min}$ under a $100 \%$ hydrogen gas atmosphere $(1 \mathrm{~L} / \mathrm{min})$ up to $400{ }^{\circ} \mathrm{C}$, where the temperature and hydrogen flow rate were then maintained for one hour. After the debinding step, argon gas was introduced to the system to produce a hydrogen partial pressure of $50 \mathrm{kPa}$ and the sample was sintered using the standard HSPT process $[6,7]$.

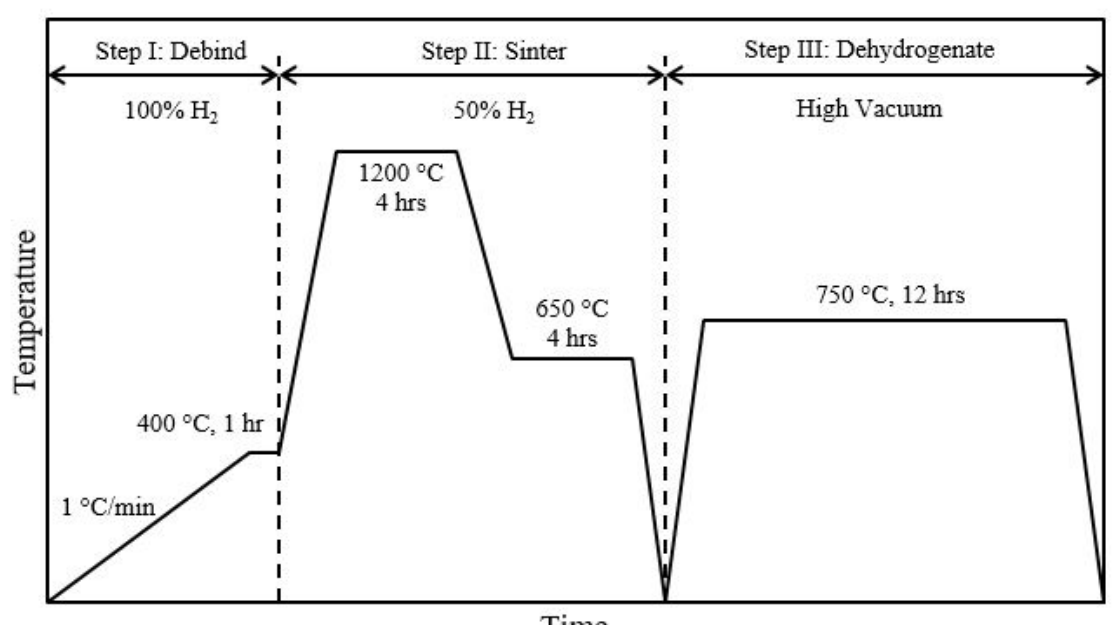

Time

Figure 1 Modified HSPT profile with thermal debinding.

Relative density was determined by the Archimedes method using a $0.1 \mathrm{mg}$ scale. A Phenom XL scanning electron microscope (SEM) with a backscattered detector was used for microstructural analysis. Oxygen and carbon analysis were performed using a Leco ONH 836 and Leco CS 230, respectively. Thermogravimetric analysis (TGA) of the TPE/MO was performed in a SDT Q600 (TA Instruments) with a balance precision of $0.1 \mu \mathrm{g}$

\section{Results \& Discussion}

\subsection{Binder Removal}

In order for a material to be a viable option as a binder, it must exhibit clean burn out characteristics. This is particularly true for titanium and its alloys, as they are very sensitive to interstitial contamination. TGA was used to examine the burn out characteristics of TPE with $67.5 \mathrm{vol} \% \mathrm{MO}$. In this analysis, the sample was incrementally heated under a $50 \% \mathrm{H}_{2}\left(\mathrm{Ar}\right.$ balance) atmosphere at $5{ }^{\circ} \mathrm{C} / \mathrm{min}$ in $50^{\circ} \mathrm{C}$ steps with a one hour dwell at each temperature. 
The results of the TGA analysis are shown in Figure 2. Significant weight loss first occurred at $\sim 150{ }^{\circ} \mathrm{C}$, which corresponds to the evaporation of MO. Weight loss accelerated significantly at 200 ${ }^{\circ} \mathrm{C}$, but plateaued at the $\sim 250^{\circ} \mathrm{C}$ step. At this point, it is assumed that all the MO had been removed. Weight loss began again at $\sim 389^{\circ} \mathrm{C}$. The vast majority of the TPE was removed during the $400{ }^{\circ} \mathrm{C}$ and all was removed during the $450^{\circ} \mathrm{C}$ step. The two main takeaways from this analysis are 1) complete removal of both the TPE and MO occur using a simple thermohydrogen debinding step and 2) debinding first begins at the relatively low temperature of $\sim 150^{\circ} \mathrm{C}$.

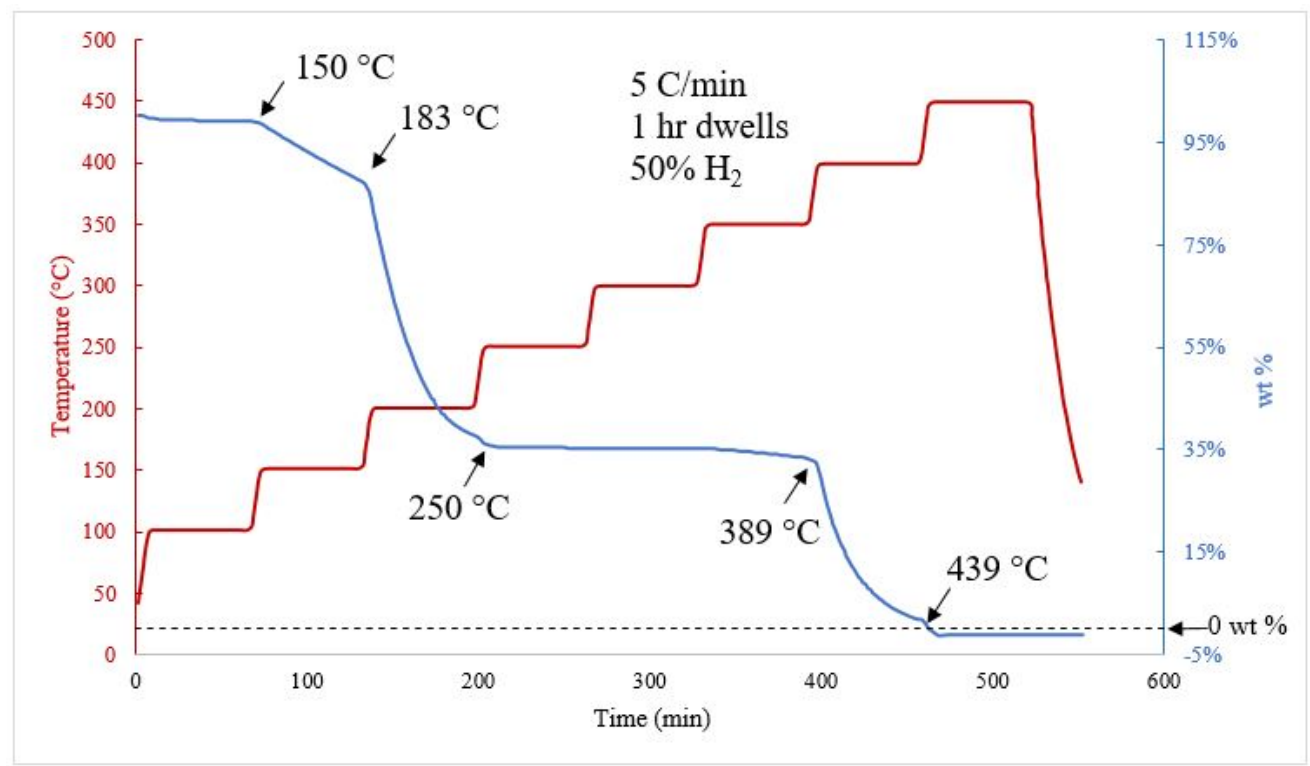

Figure 2 TGA of TPE/MO binder with $67.5 \mathrm{vol} \%$ MO.

\subsection{Sintered Filament}

Filaments were prepared using three different binder compositions (1:3, 1:1, and 3:1 TPE:MO) and two different solids loadings (50 and $60 \mathrm{vol} \%$ (Ti-6Al-4V)-H), for a total of six different conditions. The filaments were then debinded and sintered using the modified HSPT profile given in Figure 1.

SEM micrographs of the conditions after sintering are given in Figure 3. From these images, little difference can be observed across the range of binder compositions. However, two major differences are observed between the $50 \mathrm{vol} \%$ and $60 \mathrm{vol} \%$ (Ti- $6 \mathrm{Al}-4 \mathrm{~V}$ )- $\mathrm{H}$ conditions. First, the pore size is much larger in the 50 vol\% condition and it contains large $\alpha$ grains, which are absent in the 60 vol $\%$ condition. The reason for the large $\alpha$ grains in the $50 \mathrm{vol} \%$ condition will be discussed below.

From density measurements, the $50 \mathrm{vol} \%$ condition has a relative density ranging from $82-90 \%$, whereas the $60 \mathrm{vol} \%$ condition has a relative density ranging from $91-95 \%$, both ranges depending on binder composition. This significant difference in relative density can be attributed to the greater degree of inter particle contact area occurring in the 60 vol\% condition, which allows for better densification during sintering. 


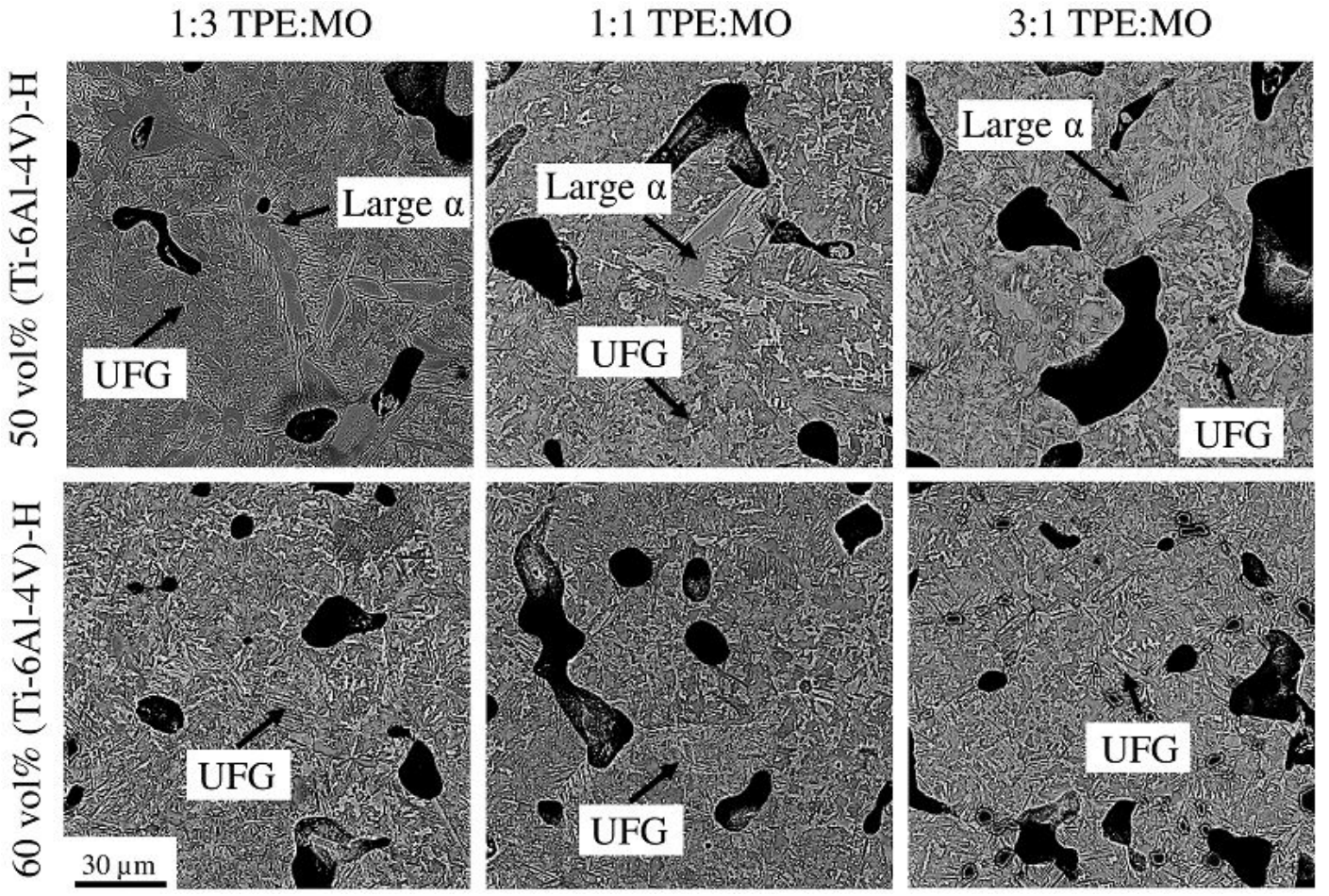

Figure 3 SEM micrographs of sintered filament with 1:3, 1:1, and 3:1 TPE:MO binder compositions and 50 vol\% and 60 vol\% (Ti-6Al-4V)-H solid loading.

The oxygen and carbon analysis of the sintered filaments is shown in Figure 4. The black $(0.3 \mathrm{wt} \% \mathrm{O})$ and red $(0.08 \mathrm{wt} \% \mathrm{C})$ dashed lines in Figure 4 correspond to the ASTM B988 limits for powder metallurgy Ti-6Al-4V, respectively [21]. From this data, it can be seen that the $60 \mathrm{vol} \%$ filament had significantly lower oxygen content and all conditions had roughly the same carbon content, though all conditions are above the ASTM limits for both interstitials. The added friction from the solids in the filament meant relatively high extrusions temperatures were required, and these extrusion were done in open air. For both the $50 \mathrm{vol} \%$ and $60 \mathrm{vol} \%$ conditions with a binder composition of $1: 3$, an extrusion temperature of $167^{\circ} \mathrm{C}$ was required. When a $3: 1$ binder was used, extrusion temperatures of $187^{\circ} \mathrm{C}$ and $230{ }^{\circ} \mathrm{C}$ were required for the $50 \mathrm{vol} \%$ and $60 \mathrm{vol} \%$ conditions, respectively.

The highest oxygen content was measured for filaments with $50 \mathrm{vol} \%(\mathrm{Ti}-6 \mathrm{Al}-4 \mathrm{~V})-\mathrm{H}$ and the higher MO contents. This is counterintuitive, as these filaments had the lower extrusion temperatures. However, all extrusions temperatures are well above the temperature at which MO began to be removed during the TGA experiments $\left(\sim 150{ }^{\circ} \mathrm{C}\right)$. Therefore, the $3: 1 \mathrm{TPE}: \mathrm{MO}$ with 50 vol $\%$ (Ti-6Al-4V)-H filament, which had the highest overall MO content ( 37.5 vol\%), likely had the most binder removed during filament extrusion. As such, more of that material would have been exposed to air at elevated temperatures during extrusion, resulting in the higher oxygen content.

It is likely that the carbon contamination came from the binder, which was composed entirely of hydrocarbons. Furthermore, since all conditions have essentially identical levels of carbon, it is likely that carbon pickup occurred during debinding step when all the binder was molten. All the conditions used identical powder, meaning the powders had the exact same specific surface area. Therefore, when the TPE melted and began to wet the powder during debinding, the same fraction of (Ti-6Al-4V)-H was in direct contact with TPE at elevated temperatures for all conditions.

As oxygen is an $\alpha$ stabilizer in titanium alloys, the presence of the large $\alpha$ grains in the $50 \mathrm{vol} \%$ (Ti-6Al-4V)-H condition can be explained by the higher degree of oxygen contamination. A similar phenomenon was observed in Ti-6Al-4V produced with (Ti-6Al-4V)-H powders having an oxygen $>1 \mathrm{wt} \%$ [22]. However, there appears to be an oxygen concentration threshold at which these large $\alpha$ grains occur. Both the $50 \mathrm{vol} \%$ and $60 \mathrm{vol} \%$ (Ti-6Al-4V)-H conditions with a binder composition of 3:1 TPE:MO have similar oxygen contents of 0.82 and $0.77 \mathrm{wt} \%$, respectively. However, only the 50 vol\% (Ti$6 \mathrm{Al}-4 \mathrm{~V}$ )- $\mathrm{H}$ condition shows these large $\alpha$ grains. Therefore, it can be concluded that this threshold exists at $\sim 0.8 \mathrm{wt} \%$ oxygen. 


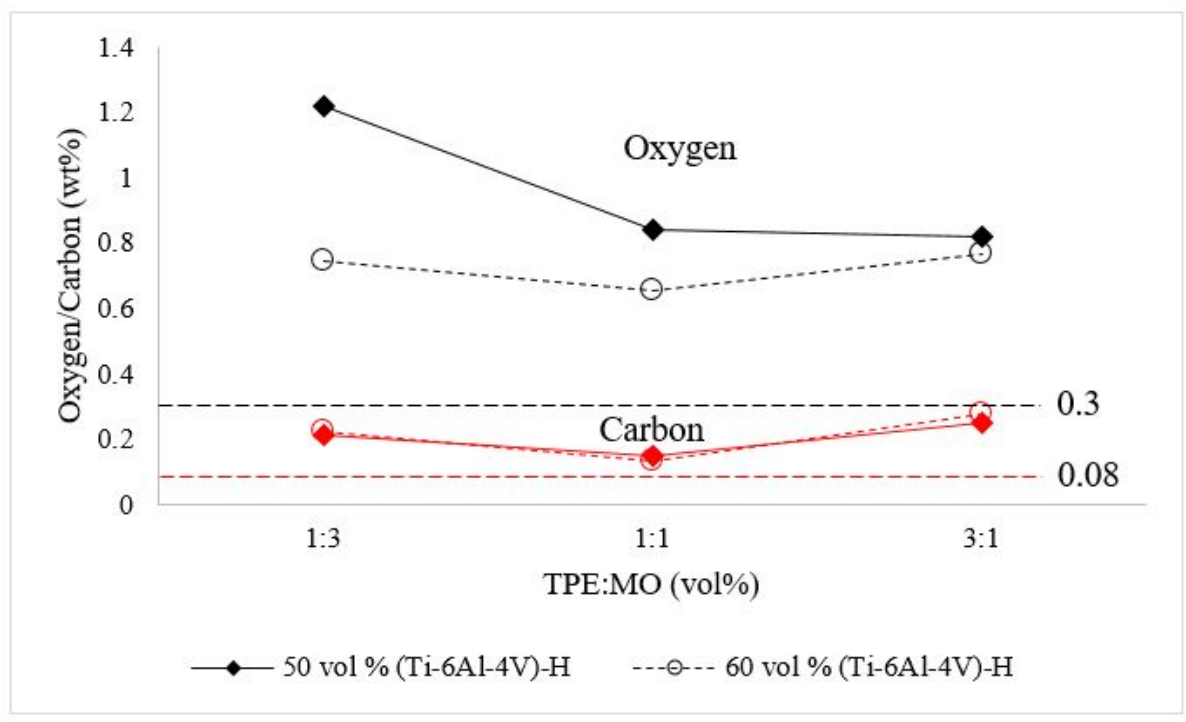

Figure 4 Oxygen and carbon content of Ti-6Al-4V produced using 50 \& 60 vol\% (Ti-6Al-4V)-H and binder compositions of 1:3, 1:1, and 3:1 TPE:MO.

\subsection{Printed Filament}

Despite the challenges associated with filament production, small cuboidal samples were printed (Figure 5). Figure 5a shows a partially printed green (not sintered) sample with a low internal infill structure, which was made to test the potential capability for complex structures. Figure $5 \mathrm{~b}$ shows a fully sintered sample with $100 \%$ infill to highlight the potential to form bulk parts. For printing, a filament with $55 \mathrm{vol} \%$ (Ti-6Al-4V)-H and a binder composition of 1:1 TPE:MO was used. This filament composition had the best combination of printability and relative density after sintering.

Unfortunately, due to the higher friction in the print head caused by the (Ti-6Al-4V)-H powder, printing proved to be difficult. Therefore, a custom-designed print head was required to prevent filament damage caused by the knurled pinch roller used in many FFF machines and to maintain stiffness of the filament as it was pushing into the liquefier. Even with this custom print head, successful printing was inconsistent. Furthermore, a print temperature of $\sim 300{ }^{\circ} \mathrm{C}$ was required to soften the filament sufficiently to allow extrusion. Therefore, further oxygen and carbon contamination could be expected in the as-printed part.

\section{Partially Printed}
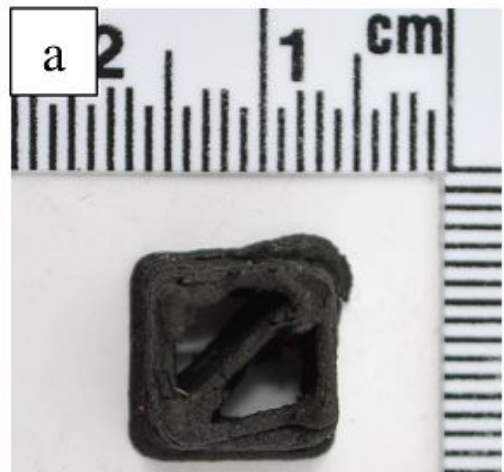

\section{As-Sintered}

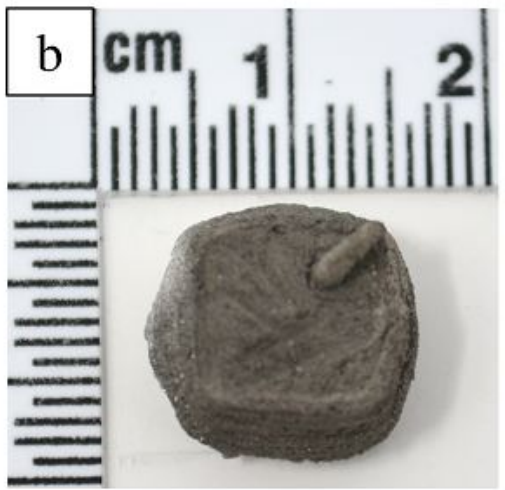


Figure 5 Samples printed with $55 \mathrm{vol} \%$ (Ti-6Al-4V)-H and a binder composition of 1:1 TPE:MO., a) partially printed sample with low infill, b) sintered sample with 100\% infill.

\section{Conclusions}

In this study, the use of a TPE/MO binder system with (Ti-6Al-4V)-H powders to produce filament for FFF printing in conjunction with the HSPT process was examined. The TPE:MO binder used in this study shows exceptional burn off characteristics under hydrogen gas. However, the binder provided insufficient protection from atmosphere during filament extrusion. Contamination was found to increase with increasing MO content in the binder, which caused the formation of large $\alpha$ grains to occur in filament produced with 50 vol\% solids loading. Small cuboidal samples were successfully printed with $55 \mathrm{vol} \%$ (Ti-6Al-4V)-H, though printing was difficult and inconsistent. With this in mind, the authors recommend further research to be conducted on identifying a replacement for MO with a higher decomposition temperature to prevent

\section{Acknowledgements}

Research was sponsored by the Army Research Laboratory and was accomplished under Cooperative Agreement Number W911NF-17-2-0145. The views and conclusions contained in this document are those of the authors and should not be interpreted as representing the official policies, either expressed or implied, of the Army Research Laboratory or the U.S. Government. The U.S. Government is authorized to reproduce and distribute reprints for Government purposes notwithstanding any copyright notation herein.

\section{References}

[1] G. Lutjering and J. Williams, Titanium, Springer, 2007.

[2] O. M. Ivasishin, D. Eylon, V. I. Bondarchuk and D. G. Savvakin, "Diffusion during Powder Metallurgy Synthesis of Titanium Alloys," Defect Diffus. Forum, vol. 277 , pp. 177 - 185, 2008.

[3] O. M. Ivasishin, D. G. Savvakin, F. Froes, V. C. Mokson, Bondareva and K. A., "Synthesis of Alloy Ti- 6Al- 4V with Low Residual," Powder Metall. Met. Ceram, vol. 41, pp. 382 - 390, 2002.

[4] O. M. Ivasishin, D. G. Savvakin, M. M. Gumenyak and O. B. Bondarchuk, "Role of Surface Contamination in Titanium PM," Key Eng. Mater, vol. 520 , pp. 121 - 132, 2012.

[5] J. Paramore, Relationship Between Processing, Structure, and Properties of Titanium Alloys Produced by Hydrogen Sintering and, Salt Lake City: University of Utah, 2015.

[6] P. Sun, Z. Z. Fang, M. Koopman, J. Paramore, K. R. Chandran, Y. Ren and J. Lu, "An experimental study of the (Ti-6Al-4V)-xH phase diagram using in situ," Acta Materialia, vol. 84, pp. 29 - 41, 2015.

[7] P. Sun, Z. Fang, M. Koopman, Y. Xia, J. Paramore, K. Chandran, Y. Ren and J. Lu, "Phase Transformations and Formation of Ultra-Fine," Metallurgical and Materials Transactions A, vol. 46A, pp. 5546 - 5560, 2015.

[8] P. Sun, Z. Fang and M. Koopman, "A Comparison of Hydrogen Sintering and Phase Transformation (HSPT) Processing with Vacuum Sintering of CP-Ti," Advanced Engineering Materials, vol. 15, pp. $1007-1013,2013$.

[9] J. Paramore, Z. Fang, P. Sun, M. Koopman, K. Chandran and M. Dunstan, "A powder metallurgy method for manufacturing Ti-6Al-4V with wrought-like microstructures and mechanical properties via hydrogen sintering and phase transformation (HSPT)," Scripta Materialia, vol. 107, pp. 103 - 106, 2015.

[10] J. Paramore, Z. Fang, M. Dunstan, P. Sun and B. Butler, "Hydrogen-enabled microstructure and fatigue strength engineering of titanium alloys," Scientific Reports, vol. 7, pp. 1 - 12, 2017. 
[11] S. Liu and Y. Shin, "Additive manufacturing of Ti6Al4V alloy: A review," Materials \& Design, vol. 164, pp. 1 - 23, 2019.

[12] M. Agarwala, A. Bandyopadhyay, R. van Weeren, N. Langrana, A. Safari and S. Danforth, "Fused deposition of ceramics (FDC) for structural silicon nitride components," in Solid Freeform Fabrication Symposium, Austin, TX, 1996.

[13] M. Agarwala, R. van Weeren, A. Bandyopadhyay, A. Safari and S. Danforth, "Filament feed materials for fused deposition processing of ceramics and metals," in Solid Freeform Fabrication Symposium, Austin, TX, 1996

[14] M. Agarwala, R. van Weeren, A. Bandyopadhyay, P. Whalen, A. Safari and S. Danforth, "Fused deposition of ceramics and metals: An overview," in Solid Freeform Fabrication Symposium, Austin, TX, 1996.

[15] M. Agarwala, R. van Weeren, R. Vaidyanathan, A. Bandyopadhyay, G. Carrasquillo, V. Jamalabad, N. Langrana, A. Safari, S. Garofalini and S. Danforth, "Structural ceramics by fused deposition of ceramics," in Solid Freeform Fabrication Symposium, Austin, TX, 1995.

[16] C. Kukla, I. Duretek, S. Schuschnigg, J. Gonzalez-Gutierrez and C. Holzer, "Properties for PIM feedstock used in fused filament fabrication," in World PM2016, Hamburg, Germany, 2016.

[17] C. Burkhardt, P. Freigassner, O. Weber, P. Imgrund and S. Hampel, "Fused filament fabrication (FFF) of 316L green parts for the MIM process," in World PM2016, Hamburg, Germany, 2016.

[18] S. Riecker, J. Clouse, T. Studnitzky, O. Andersen and B. Kieback, "Fused deposition modeling - opportunities for cheap metal AM," in World PM2106, Hamburg, Germany, 2016.

[19] J. Mireles, D. Espalin, D. Roberson, B. Zinniel, F. Medina and R. Wicker, "Fused deposition modeling of metals," in Solid Freeform Fabrication Symposium, Austin, TX, 2012.

[20] J. Gonzalez-Gutierrez, S. Cano, S. Schuschnigg, C. Kukla, J. Sapkota and C. Holzer, "Additive manufacturing of metallic and ceramic components by the material extrusion of highly-filled polymers: a review and future perspectives," Materials, vol. 11, pp. 1-36, 2018.

[21] ASTM International, "ASTM B988: Standard Specification for Powder Metallurgy (PM) Titanium and Titanium Alloy Structural Components," ASTM International, West Conshohocken, PA, 2013.

[22] M. Dunstan, A. Gordon, J. Paramore and B. Butler, "Feasibility of Using Titanium Machine Turnings in Powder," JOM, vol. 71, pp. 1831 - $1839,2019$. 